\title{
Impact of Psychiatric Disorders on the Quality of Life of Brazilian HCV-Infected Patients
}

\author{
Susana Batista-Neves ${ }^{1}$, Lucas C. Quarantini ${ }^{1,2}$, Amanda Galvão-de Almeida ${ }^{1}$, Maurício Cardeal ${ }^{1}$, Acioly L. Lacerda ${ }^{2}$, Raymundo \\ Paraná $^{3}$, Irismar Reis de-Oliveira ${ }^{1}$, Rodrigo A. Bressan ${ }^{2}$ and Angela Miranda-Scippa ${ }^{1}$ \\ ${ }^{1}$ Federal University of Bahia - Hospital Universitário; ${ }^{2}$ Federal University of São Paulo - Laboratório Interdisciplinar de Neurociências Clínicas \\ (LiNC); São Paulo, SP, Brazil; ${ }^{3}$ Federal University of Bahia - Hospital Universitário - Unidade de Hepatologia; Salvador, BA, Brazil
}

\begin{abstract}
The aim of our study was to determine the impact of psychiatric comorbidities on the health-related quality of life of $\mathrm{HCV}$-infected patients. Assessment of clinical, socio-demographic and quality of life data of the patients followed up at a Hepatology unit was performed by using a standard questionnaire and the SF-36 instrument. Psychiatric diagnoses were confirmed by using the Mini International Neuropsychiatric Interview, Brazilian version 5.0.0 (MINI Plus). Evaluation using the MINI plus demonstrated that $46(51 \%)$ patients did not have any psychiatric diagnosis, while $44(49 \%)$ had at least one psychiatric diagnosis. Among patients with a psychiatric comorbidity, 26 (59.1\%) had a current mental disorder, out of which $22(84.6 \%)$ had not been previously diagnosed. Patients with psychiatric disorders had lower scores in all dimensions of the SF-36 when compared to those who had no psychiatric diagnosis. Scores of physical functioning and bodily pain domains were lower for those suffering from a current psychiatric disorder when compared to those who had had a psychiatric disorder in the past. Females had lower scores of bodily pain and mental health dimensions when compared to males. Scores for mental health dimension were also lower for patients with advanced fibrosis. The presence of a psychiatric comorbidity was the variable that was most associated with the different scores in the SF-36, compared to other variables such as age, gender, aminotransferase levels, and degree of fibrosis.
\end{abstract}

Key-Words: Mental disorders, quality of life, HCV.

Hepatitis $\mathrm{C}$ virus (HCV) infection is a public health problem throughout the world. In Brazil, its prevalence is estimated to be $2.5 \%-4.0 \%$ of the general population [1]. This disease progresses slowly and evolves into chronic infection in $85 \%$ of the cases, of which 20 to $30 \%$ may develop liver cirrhosis [2].

Different studies have reported impairment in healthrelated quality of life (HRQOL) in patients with chronic hepatitis $\mathrm{C}(\mathrm{CHC})$ infection, when compared to the general population [3-5]. Factors such as presence of clinical comorbidities, including psychiatric ones, stage of liver disease, awareness of diagnosis and neurocognitive alterations, have been associated with this impairment, although there is no consensus as to what is the main determinant of the decrease in HRQOL among these patients [6-12]. The majority of the studies concerning HRQOL of patients with $\mathrm{HCV}$ infection have not investigated psychiatric comorbidities nor do they adequately measure the impact of such an association [13]. Some of them merely evaluate depression and anxiety symptoms by using self-rating instruments, or seek out this information in medical files on the patient's chart, which may not accurately reflect the mental state of these patients $[5,8,14]$.

The objective of our study was to determine the impact of psychiatric comorbidities on the HRQOL of HCV-infected patients.

Received on 7 June 2008; revised 11 December 2008

Address for correspondence: Dr. Lucas C. Quarantini: Hospital Universitário Professor Edgard Santos- Serviço de Psiquiatria- $3^{\circ}$ andar. Rua Dr. Augusto Viana S/N. Zip code: 40110-909 - Salvador - BA - Brazil. Phone: 55-713332-3509 / Fax: 55-11-3332 3509. E-mail: 1cq@ufba.br.

\section{Material and Method \\ Participants}

Patients were included if they tested positive for anti-HCV antibody by the ELISA III method (Abbott, Chicago, IL), confirmed by qualitative and/or quantitative determination of HCV-RNA by AMPLICOR (Roche, Basel). The exclusion criteria were: current or previous treatment with interferon (IFN) during the previous three months, presence of nonpsychiatric comorbidity such as hypertension, diabetes mellitus, hypothyroidism, or other medical conditions with systemic repercussion, current use of propranolol or other drugs associated with an increased risk of psychiatric symptoms, cirrhosis classified as Child Pugh B and C or liver disease decompensation. This study was done in accordance with the Declaration of Helsinki and was approved by the local Institutional Review Board. Written informed consent was obtained from each patient.

\section{Procedures}

Assessment of clinical and socio-demographic data was performed by using a standard questionnaire; we also included aminotransferase levels from the last measurement recorded on the chart and the degree of fibrosis as measured by hepatic biopsy, according to METAVIR classification [15]. Psychiatric diagnoses were confirmed by using a Brazilian version of the Mini International Neuropsychiatric Interview, 5.0.0 (MINI Plus) [16], consisting of a brief standardized diagnostic interview that encompasses the main axis I disorders of the Diagnostic and Statistical Manual of Mental Disorders (DSM IV-American Psychiatric Association, 1994) and the International Classification of Diseases (ICD-10World Health Organization-WHO, 1992). Before using MINI Plus, a reliability study with two interviewers (LCQ, SB-N) was performed. 
HRQOL was evaluated by using the Medical Outcomes Study 36-Item Short-Form Health Survey (SF-36), which is a self-administered as well as a generic instrument, previously validated in Portuguese [17]. The SF-36 is composed of 36 items divided into eight dimensions: physical functioning, physical role, bodily pain, general health, vitality, social functioning, emotional role and mental health. Scores in each dimension vary from zero to 100 , representing the worst and the best state of health, respectively.

\section{Data Analysis}

The data were entered into EPIDATA software version 3.1 and analyzed with the R Package program version 2.3.1. $[18,19]$. The measurements of epidemiological occurrence and association were calculated, as well as the $95 \%$ confidence interval, prevalence and prevalence rate. Analysis of parametric variance was performed in order to investigate the joint contribution of predictor variables in explaining the variability of each dimension. The Student's t-test for independent samples and the Mann-Whitney test were used to compare the groups of the study in relation to each dimension.

\section{Results}

In this cross-sectional study, 95 consecutive outpatients with $\mathrm{CHC}$ from the University Hospital Liver Unit provided written informed consent. Five of these later declined and removed consent. The final study sample consisted of 90 individuals. Their ages ranged from 20 to 64, with a median of 45 years. Of these, $50(55.5 \%)$ were male and $40(44.4 \%)$ were female. The majority of the patients were married $(58.9 \%)$. Thirty percent of HCV-infection transmission was through blood transfusions; other means of infection included razor blades, dental procedures, vitamin complex injections (14.4 $\%$ ), use of injected drugs (8.9\%), and tattooing (2.2\%), while $44.4 \%$ did not know the means of infection (Table 1 ).

Aminotransferase levels were altered in $59(65.5 \%)$ of the patients with $\mathrm{CHC}$ infection and 30 (33.3\%) presented persistently normal rates. Forty-nine $(54.5 \%)$ patients were submitted to biopsy, nine of them (18.4\%) presented fibrosis stage $1 ; 24$ (49\%) presented fibrosis stage $2 ; 12(24.5 \%)$ presented stage 3 ; and four $(8.2 \%)$ demonstrated cirrhosis. The majority of the patients ( $77-85.5 \%)$, had no prior antiviral treatment, while $13(14.4 \%)$ had been treated more than three months before. Fifty (55.5\%) had HCV genotype 1 and 20 $(22.2 \%)$ had genotypes 2 and 3 (Table 2 ).

Evaluation using MINI plus demonstrated that 46 (51\%) patients did not have any psychiatric diagnosis while 44 (49\%) had at least one psychiatric diagnosis. Among those with a psychiatric comorbidity, $16(36.4 \%)$ had two or more psychiatric diagnoses. The frequency found was: $26(28.9 \%)$ with alcohol and other substance abuse or dependence, 17 $(18.9 \%)$ with mood disorders and 14 (15.6\%) with anxiety disorders. Among patients with a psychiatric comorbidity, 26 (59.1\%) had a current mental disorder, out of which $22(84.6 \%)$ had not been previously diagnosed.
Patients whose aminotransferase levels were elevated had $53 \%$ more psychiatric disorders than those with normal aminotransferase levels; though this difference was not significant $(p>0.05)$. The presence of advanced fibrosis (stage 3 or 4 ), prior treatment, age $\geq 40$ years or female gender did not have a significant association with psychiatric disorders.

Patients with psychiatric disorders (past and current) had lower scores in all of the eight dimensions of the SF-36, when compared to those who had no psychiatric diagnosis $(\mathrm{p}<$ 0.05 , Figure 1). Scores of physical functioning and bodily pain domains were lower for those suffering from a current psychiatric disorder when compared to those who had had a psychiatric disorder in the past ( $p<0.05$, Figure 2$)$. Females had lower scores of bodily pain and mental health dimensions when compared to their male counterparts $(p<0.05)$. Scores for mental health dimension were also lower for patients with advanced fibrosis $(\mathrm{p}<0.05)$.

\section{Discussion}

We found that psychiatric comorbidity was the variable that was most associated with the different scores on the SF36 , compared to other variables such as age, gender, aminotransferase levels, and degree of fibrosis.

Additionally, patients with a current psychiatric comorbidity had lower scores in only two dimensions (physical functioning and bodily pain), when compared to those who had experienced psychiatric morbidity in the past. This result is difficult to explain because having a current disorder could be associated with greater loss in all dimensions, since psychiatric symptoms can worsen HRQOL, as reported in other studies [14,20].

Other authors who have also used a standardized diagnostic interview have demonstrated that depression is associated with low SF-36 scores; although in these studies $\mathrm{HCV}$-infected patients undergoing treatment with IFN were not excluded, which could have interfered negatively in the assessment of HRQOL and increased the incidence of psychiatric events [21-24].

Similar to most previously-published studies, the liver aminotransferase levels were not related to SF-36 scores, perhaps because they were not associated with increased rates of psychiatric comorbidity [5,8,9,25-27]. Patients with $\mathrm{CHC}$ that presented more advanced fibrosis (stage 3 and 4) did not differ in their SF-36 scores, except in the dimension of mental health, in comparison to those who presented less advanced fibrosis (stage 1 and 2). Most studies have not demonstrated an association between stage of fibrosis and quality of life, except in cases of advanced cirrhosis $[3,8,9,14,20,28,29]$. In our study, only $54.5 \%$ were submitted to a biopsy and only four of them $(8.2 \%)$ had cirrhosis. Furthermore, the small number of intravenous drug users is consistent with previous reports regarding the route of infection in Brazil [21,30,31]. Therefore, it may not be possible to generalize these results to our population. 
Table 1. Socio-demographic data and sources of HCV infection in patients treated at the Hepatology Unit, University Hospital, Bahia, Brazil.

\begin{tabular}{lcc}
\hline Variables & $\mathbf{N}$ & $\mathbf{\%}$ \\
\hline Gender & & \\
$\quad$ Male & 50 & $55.5 \%$ \\
$\quad$ Female & 40 & $44.4 \%$ \\
Age & & \\
$\quad<40$ & 20 & $22.2 \%$ \\
$\geq 40$ & 70 & $77.8 \%$ \\
Marital status & & \\
Married & 53 & $58.9 \%$ \\
Separated/Widow(er) & 14 & $15.5 \%$ \\
Single & 23 & $25.5 \%$ \\
Sources of infection & & \\
$\quad$ Transfusion/surgery & 27 & $30.0 \%$ \\
$\quad$ Injected Drug Use & 8 & $8.9 \%$ \\
Tatoo & 2 & $2.2 \%$ \\
Others (razor blades, dental procedures, vitamin complex injections) & 13 & $14.4 \%$ \\
$\quad$ Unknown & 40 & $44.4 \%$ \\
\hline
\end{tabular}

Table 2. Characteristics of chronic hepatitis $\mathrm{C}$ in patients treated at the Hepatology Unit, University Hospital, Bahia, Brazil.

\begin{tabular}{lcc}
\hline Variables & $\mathbf{N}$ & $\mathbf{\%}$ \\
\hline Aminotransferase & & \\
$\quad$ Normal rate & 30 & $33.3 \%$ \\
$\quad$ Elevated rate & 59 & $65.5 \%$ \\
$\quad$ Had no result & 1 & $1.1 \%$ \\
Biopsy W/Fibrosis & & \\
$\quad$ Stage 1 or 2 & 33 & $36.7 \%$ \\
$\quad$ Stage 3 or 4 & 16 & $17.8 \%$ \\
$\quad$ Did not do biopsy & 41 & $45.5 \%$ \\
Genotype & & \\
$\quad$ 1 & 50 & $55.5 \%$ \\
2 or 3 & 20 & $22.2 \%$ \\
$\quad$ Genotype unknown & 20 & $22.2 \%$ \\
Prior treatment & & \\
$\quad$ Yes & 13 & $14.4 \%$ \\
$\quad$ No & 77 & $85.5 \%$ \\
\hline
\end{tabular}

In conclusion, our data suggest that a psychiatric comorbidity is an important factor influencing quality of life among HCV-infected patients. Further investigations with larger sample sizes are necessary to provide better information to confirm our findings.

\section{Acknowledgments}

We thank Dr. Rozana Ciconelli, Dr. Guilherme Lyra, Dr. André Lyra, Dr. Nelma Santana, Dr. Eduardo Braga, Dr. Mateus Fiúza, Dr. Maria Isabel Schinoni, Dr. Simone Cunha, Dr. Viviane Mello, Dr. Lívia Dantas, Katiucha Abreu, Ilka Moura, Juliana Pinto, Marianna Lima, Alberto Junqueira, Marco Sena, and Dr. Dimitri Gusmão Flores for clinical and technical assistance. This study was partially supported by grants from the Foundation for the Support of Research in the State of Bahia (FAPESB), the Brazilian Ministry of Education, and the Association of the Post-Graduation Course in Medicine and Health (CAPES).

\section{References}

1. Hepatitis C-global prevalence (update). Wkly Epidemiol Rec 2000;75:18-9.

2. Seeff L.B., Hoofnagle J.H. National Institutes of Health Consensus Development Conference Panel Statement: Management of Hepatitis C: 2002. Hepatology 2002;36(suppl 1):S1-S2.

3. Foster G.R., Goldin R.D., Thomas H.C. Chronic hepatitis C virus infection causes a significant reduction in quality of life in the absence of cirrhosis. Hepatology 1998;27:209-12.

4. Bonkovsky H.L., Woolley J.M., the Consensus Interferon Study Group. Reduction of health-related quality of life in HCV and improvement with interferon therapy. Hepatology 1999;29:264-70. 
Table 3. Association between psychiatric disorders and clinical-demographic characteristics of chronic hepatitis $\mathrm{C}$ patients, Bahia, Brazil.

\begin{tabular}{lccc}
\hline & Psychiatric disorders & PR & $\mathbf{9 5 \%}$ CI \\
\hline Aminotransferase & & & \\
$\quad$ Elevated rates & $55.9 \%$ & 1.53 & {$[0.91-2.57]$} \\
$\quad$ Normal rates & $36.7 \%$ & & \\
$\quad$ Fibrosis & $62.5 \%$ & 1.15 & {$[0.70-1.87]$} \\
$\quad$ Stage 3 or 4 & $54.5 \%$ & & \\
$\quad$ Stage 1 or 2 & $61.5 \%$ & 1.32 & {$[0.81-2.15]$} \\
Prior Treatment & $46.8 \%$ & & \\
$\quad$ Yes & & & \\
$\quad$ No & $47.5 \%$ & 0.95 & {$[0.62-1.43]$} \\
Gender & $50.0 \%$ & & \\
$\quad$ Female & & & \\
$\quad$ Male & $51.4 \%$ & 1.29 & \\
Age & $40.0 \%$ & & \\
$\quad \geq 40$ years & & & \\
$\quad<40$ years & & & \\
\hline
\end{tabular}

$\mathrm{PR}=$ prevalence rate. $\mathrm{CI}=$ confidence interval.

5. Fontana R.J., Moyer C.A., Sonnad S. et al. Comorbidities and quality of life in patients with interferon refractory chronic hepatitis C. Am J Gastroenterol 2001;96:170-8.

6. Rodger A.J., Jolley D., Thompson S.C. et al. The Impact of Diagnosis of Hepatitis C Virus on Quality of Life. Hepatology 1999;30:1299-301.

7. Dalgard O., Egeland A., Skaug K. et al. Health-related of life in active injecting drug users with and without chronic hepatitis $\mathrm{C}$ virus infection. Hepatology 2004;39:74-80.

8. Hussain K.B., Fontana R.J., Moyer C.A. et al. Comorbid illness is an important determinant of health-related quality of life in patients with chronic hepatitis C. Am J Gastroenterol 2001;26:2737-44.

9. Younossi Z.M., Boparai N., Price L.L. et al. Health-related quality of life in chronic liver disease: the impact of type and severity of disease. Am J Gastroenterol 2001;96:2199-200.

10. Cordoba J., Flavia M., Jacas C. et al. Quality of life and cognitive function in hepatitis $\mathrm{C}$ at different stages of liver disease. $\mathrm{J}$ Hepatol 2003;39:231-8.

11. Lim J.K., Cronkite R., Goldstein M.K., Cheung R.C. The impact of chronic hepatitis and comorbid psychiatric illnesses on healthrelated quality of life. J Clin Gastroenterol 2006;40:528-34.

12. Forton D.M., Taylor-Robinson S.D., Thomas H.C. Cerebral dysfunction in chronic hepatitis $\mathrm{C}$ infection. J Viral Hepat 2003; 10 :66-81.

13. Batista-Neves S.C., Quarantini L.C., Galvão-Almeida A. et al. High frequency of unrecognized mental disorders in $\mathrm{HCV}$-infected patients. Gen Hosp Psychiatry 2008;30:80-2.

14. Gallegos-Orozco J.F., Fuentes A.P., Argueta J.G. et al. Health related quality of life and depression in patients with chronic hepatitis C. Arch Med Res 2003;34:124-9.

15. Bedossa P., Poynard T. An algorithm for the grading of activity in chronic hepatitis C. The METAVIR Cooperative Study Group. Hepatology 1996;24:289-93.

16. Amorim P. Mini International Neuropsychiaric Interview (MINI): validação de entrevista breve para diagnóstico de transtornos mentais. Rev Bras de Psiquiatr 2000;22:106-15.

17. Ciconelli R.M., Ferraz M.B., Santos W.S. et al. Tradução para a língua portuguesa e validação do questionário genérico de avaliação de qualidade de vida "Medical Outcome Study 36-Item Short Form Health Survey (SF-36)". Rev Bras Reumatol 1999;39:143-50.

18. Lauritsen J.M., Bruus M. EpiData (version 3). A comprehensive tool for validated entry and documentation of data. The EpiData Association, Odense Denmark, 2003-2004.
19. R Development Core Team (2006). R: A language and environment for statistical computing. R Foundation for Statistical Computing, Vienna, Austria. ISBN 3-900051-07-0, URL http:/ /www.R-project.org. 2006.

20. Rowan P.J., Al-Jurdi R., Tavakoli Tabasi S., et al. Physical and psychosocial contributors to quality of life in veterans with hepatitis C not on antiviral therapy. J Clin Gastroenterol 2005;39:731-6.

21. Quarantini L.C., Miranda-Scippa A., Schinoni M.I., et al. Effect of amantadine on depressive symptoms in chronic hepatitis $\mathrm{C}$ patients treated with pegylated interferon: a randomized, controlled pilot study. Clin Neuropharmacol 2006;29:138-43.

22. Quarantini L.C., Miranda-Scippa A., Sampaio A.S., et al. Acute dystonia after injection of pegylated interferon alpha-2b. Mov Disorders 2007;22:747-8.

23. Quarantini L.C., Cruz S.C., Batista-Neves S.C., et al. Psychosis during Peginterferon- $\alpha 2 \mathrm{a}$ and ribavirin therapy: case report. Braz J Infect Dis 2006;10:406-7.

24. Lotrich F.E., Rabinovitz M., Gironda P., Pollock B.G. Depression following pegylated interferon-alpha: Characteristics and vulnerability. J Psychosom Res 2007;63(2):131-5.

25. Miller R.E., Hiller J.E., Shaw D.R. Quality of life in HCV-infection: lack of association with ALT levels. Aust N Z J Public Health 2001;25:355-61.

26. Schwarzinger M., Dewedar S., Rekacewicz C., et al. Chronic hepatitis $\mathrm{C}$ virus infection: does it really impact health-related quality of life? A study in rural Egypt. Hepatology 2004;40:1434-41.

27. Von Wagner M., Lee J.-H., Kronenberger B., et al. Impaired healthrelated quality of life in patients with chronic hepatitis $\mathrm{C}$ and persistently normal aminotransferase levels. J Viral Hepat 2006; $13: 828-834$

28. Teixeira M.C.D., Ribeiro M.F.G.S., Gayotto L.C.C., et al. Worse quality of life in volunteer blood donors with hepatitis C. Transfusion 2006; 46 :278-83.

29. Marchesini G., Bianch G., Amodio P., et al. Factors Associated With Poor Health-Related Quality of Life of Patients With Cirrhosis. Gastroenterology 2001;120:170-8.

30. Parana R., Lyra L., Trepo C. Intravenous vitamin complexes used in sporting activities and transmission of HCV in Brazil. Am J Gastroenterol 1999;94:857-8.

31. Quarantini L.C., Bressan R.A., Galvão-de Almeida A., et al. Incidence of psychiatric side effects during pegylated interferon alpha retreatment in nonresponder hepatitis $\mathrm{C}$ virus-infected patients. Liver International 2007;27:1098-102. 